\title{
The Chinese "Togetherness-Separation" Paradox: An Analytical Approach to Understanding Chinese People's Behavior and Its Implication to International Cooperation
}

\author{
Miguel A. Cerna ${ }^{1}$ \\ ${ }^{1}$ Dong Hua University, China \\ Correspondence: Miguel A. Cerna, Dong Hua University, China. E-mail: miguel.cerna@icloud.com
}

Received: September 6, 2015

Accepted: October 12, $2015 \quad$ Online Published: November 25, 2015

doi:10.5539/ijbm.v10n12p194

URL: http://dx.doi.org/10.5539/ijbm.v10n12p194

\begin{abstract}
This investigation takes an explanatory approach to Chinese paradoxical behavior and sheds light upon one the most recent findings regarding, what I called, the "togetherness-separation" paradox of the Chinese society. It includes data collected in Mainland China between 2010 and 2012 from Chinese and non-Chinese professionals working in Shanghai, Guangzhou, Hangzhou and Beijing in different fields including international trade, sourcing, logistics, compliance, quality control, supply chain consultancy, diplomacy and education. Respondents were presented with twenty-six aspects, divided in three categories, seemingly affecting cross-cultural interactions at work including Attitude (determined by values): Friendliness, being active and positive, responsibility, good demeanor, sociability, willingness to learn, flexibility, sense of humor and being humble; Education and skills (determined by education systems): Academic background, foreign language capability, mother tong, creativity, school attended, credentials, interests, communication skills, good command of English and intellectual curiosity; and Physical aspects (determined by race and clothing): Age, general appearance, gender, height, skin color, clothing, and health appearance.

The differences between Chinese and Non-Chinese managers found in this investigation, are explained based on literature review as well as on an in-depth interview with Prof. RongYao Chen expert in Chinese organizational cultural and Prof. of Business Administration at Donghua University, Shanghai campus. Cluster analysis shows that non-Chinese professional share a common mindset regarding what they consider most and least important to carry out working cross-cultural interactions, while the Chinese professionals, as a group, show to be dispersed.
\end{abstract}

Keywords: culture paradox, globalization, international cooperation, cross-cultural cooperation, Chinese behavior, collectivism, individualism

\section{Introduction}

The issue of conflict between people from China and those from other countries has been largely studied (Chen \& Miller 2010; Fang, 1999; Blackman, 1997; Chen, 1995; Child, 1993; Chu, 1993, 1992; Pye, 1990; Locket, 1988), but very few of those studies have been conducted with international managers based in modern China. Most questionnaire-based studies are conducted with students that don't have the necessary organizational experience to provide information that is accurate in terms of day-to-day organizational reality.

Chinese people are anything but easy for western visitors to understand, yet increasing globalization, especially in China, makes it necessary to comprehend the thinking processes behind Chinese people's attitudes and behavior. Contemporary China may seem in many ways different from what it was during the Qing Dynasty or any earlier periods. Tangible changes such as architecture, infrastructure and clothing in some areas of China are obvious, but in the realm of the intangible world, things might remain very much the same, that is Chinese people's paradoxical behavior continues to be a puzzle for the western visitor.

Known as a collectivistic country (Hofstede, 1980; Pratt, 1991), one would expect that Chinese people, as a homogenous group would show a united mindset, which, observing them during daily commuting, seems to be the case. However, and regardless of their similarities, this research shows a different picture.

China is an entangled society where togetherness and separation coexist. The question arises as to when are Chinese people together and when are they apart? Based on an important finding in the course of a much larger 
investigation regarding cross-cultural interactions conducted by this investigator, this document attempts answered this question and the paradox mentioned above.

\section{Theoretical Framework}

\subsection{Passivity and Proactivity}

One characteristic of Chinese people is their duality of thoughts expressed through their attitudes and behaviors. Sometimes they are proactive, and some times (along a continuum) they turn into passivity, which discourages most westerners. Two indigenous cultural elements, Confucianism and Taoism, wire the Chinese mentality (Weber, 1951; Tang, 1991; Fang, 2001). Confucianism is a form of moral ethic as well as a practical teaching of interpersonal relationships, whereas Taoism is concerned with creativity of life and harmony with nature. Buddhism, calls for proactivity to develop the self in order to find a place in society. Based on this philosophy, Chinese people are educated to seek a place higher and better than the others in their immediate surroundings through building relationships that are based on reciprocity and mutual adaptation. The Confucian tradition can be understood in terms of moral cultivation, the importance of interpersonal relationships, family orientation, respect for age and hierarchy, avoidance of conflict and need for harmony, and the Chinese concept of face. (Fang, 2001). This philosophy seems paradoxical in nature, on the one hand it call for proactivity to escalate social strata, and at the same time calls for harmony and conflict avoidance. Taoism, calls for passive acceptance of the unchangeable events of life, which may explain Chinese people's ability to face the highly stressful situations with apparent calm and cold attitude as well as follow leading figures without questioning. Taoism refers to the traditional Chinese schemes with which the Chinese cope with various kinds of situations to gain material and psychological advantage over the opponents. (idem). Here again we see a paradox since that passivity contrasts with the later call for competitive advantages.

Both, Confucianism and Taoism enter the Chinese brain at the earliest stage of life. The first doctrine to enter the mind of Chinese people is Taoism, normally not through a formal religious or systematic learning process, but through an informal way of experiencing society at home and in their neighborhoods. It's within these settings that they learn to accept life as it is and respect hierarchy without question. The second line of thoughts, Confucianism, reinforces their mentality from the early years at school, where they are taught to be competitive against their fellow students, but not so against their teachers (influence of Taoism). Obedience and respect for hierarchy is here reinforced. It is this competitive element in Chinese society where separation within the wider society may occur and develops the paradox inherent in Chinese culture that is "the simultaneous presence of contradictory, even mutually exclusive elements", (Cameron \& Quinn, 1999, p. 2; Fang, 2005-2006, p. 76). These two cultural forces, or rather, the mixture of them, develop into the high complexity of the Chinese societies, including the societies within working environments.

\subsection{China's Managerial Paradoxes in Modern China}

Contradictions in Chinese behavior create frustration among foreigners because we do not where they come from and hence don't know what to expect. From the opening of China more than three decades ago, multinational organizations continue to establish businesses in this country, many of them have not achieved the success they expected. In fact, foreign managers have often reported frustration and confusion when doing business in China (Zhao, 2000) mainly due to observable inconsistencies. This investigator frequently ask foreign professionals regarding their experience working in China, and the impression continues to be that it is frustrating due to much uncertainty. "Change" is found to be the most important keyword that foreign managers tend to use when describing Chinese culture and Chinese business behavior since 1978 when China's "open-door" policy was implemented (Fang \& Worm 2008). Tony Faure and Guy Oliver Fang (2010) developed a comprehensive study of Chinese business negotiation process, and identified eight paradoxical values presented briefly below with slight adaptations by this investigator:

\subsubsection{Paradox 1) Guanxi vs. Professionalism}

Guanxi (关系, interpersonal relationships, personal connections) plays a fundamental role in the conduct of business in Chinese (Luo, 2000) since nothing can be done in Chinese society without guanxi (Leung, 2008 Sherriff, \& Wong, 1985; Redding, 1995). However, to foster economic reform, China has adopted and emphasized the importance of the principles of meritocracy and open competition: this has slowly but surely stimulated managers to base their success on professional abilities and not merely on guanxi. Consequently, today's Chinese business culture relies increasingly on a mixture in which guanxi and renqing (人情 personal feeling; personal favor) are counterbalanced by high degrees of professionalism. Thus, conducing successful business in today's China demands both personal relationships (guanxi) and professional abilities (能力 nengli). 
This researcher sustains that guanxi is a must in all societies, the difference resides and the means to build that guanxi. This difference is by itself a generator of conflict. If one party finds the means to guanxi unceptable, unethical or unnecessary, that guanxi may not ever be established.

\subsubsection{Paradox 2) Face vs. Self-Expression}

Freedom, self-expression, and quality of life are some of the values that are fostered by economic growth in China (Inglehart \& Welzel, 2005; Leung, 2006). Although Chinese people are traditionally face-conscious, reserved in their display of emotions and indirect in their communication (Gao, et al, 1996-1998), professionals of today's China have started to increasingly show a quite different behavior so as to face intense global competition. Thus, while face and humility are still valued, Chinese professionals now tend to project confidence and openness. This is exemplified in a highly publicized advertisement from China Mobile, for example, the world's largest mobile phone operator, in which a confident Chinese manager speaks into his mobile phone with the text displaying “I can!” (我能 Wo neng!) (Faure \& Fang, 2008).

\subsubsection{Paradox 3) Thrift vs. Materialism}

Identified as one of the attributes of Confucian Dynamism (Bond \& Hofstede, 1989), thrift is still a highly valued virtue in today's China. Yet, with the enormous economic growth that has characterized the country for three consecutive decades, the rising living standards, and the consequent wider availability of consumer goods, a hedonistic lifestyle has also started to emerge among a growing segment of China's population. Consequently, foreign luxury brands such as Rolex, Dior, Gucci, Channel, Louis Vuitton and Armani have found in China a ready and fertile market. Put another way, "The philosophy is 'enjoy life today' against the old Chinese custom of saving, saving, saving" (China Luxury, 2007).

\subsubsection{Paradox 4) Family Collectivism vs. Individualism}

Family has been and still is the basic unit of Chinese society, in so much as sterility was traditionally viewed as the biggest moral crime. Today, choosing to have children at a later age or not to have children at all is no longer a source of shame and gossips in the cities, as evidenced by the growing number of Chinese 'double income no kids' (DINK) families. Young Chinese managers, and in particular those born after 1980 (often referred to as “post-80" (80 后 balinghou), tend to give priority to their personal goals, thus suggesting a more individualistic orientation to life (Zhang, 2007). Nowadays, Chinese society allows people to pursue their own interest as well as that of their organization, something that contributes to the emergence of a paradoxical behavior which emphasizes both personal pursuit (个人追求 geren zhuiqiu) and dedication to the organization and society within the in-groups (奉献 fengxian).

\subsubsection{Paradox 5) Rule by man vs. Rule of Law}

Chinese society has traditionally been governed by the rule of man rather than by the rule of law. In this light, laws are viewed as something to be circumvented and/or adapted to suit the rule by man, while legalism has never played a powerful role in society. However, with the opening of China to foreign investment, the need to establish a legal framework has emerged. This has affected, for instance, the way lawyers are viewed in society: considered outcasts during the Cultural Revolution (1966-1976), lawyers are now highly valued in China, since Chinese enterprises need legal experts to conclude commercial contracts and conduct international business negotiations. A further example of China's increased respect for legal practices is the China's New Labor Contract Law that came into effect on January 1, 2008, and which aims to improve employees' working condition and welfare.

\subsubsection{Paradox 6) Respect for Age vs. Meritocracy}

Traditionally, the father is the final decision maker in the Chinese family. Nowadays, however, children often earn substantially more than their fathers. This new economic reality challenges the traditional Chinese hierarchy and the unquestioned authority of the father, and affects everyday-life behaviors and value orientations. This means, for examples, that it is now considered normal for the junior member of the family to pay the bill when the family eats out (Faure \& Fang, 2008). While seniority is still valued, it is now counterbalanced by a growing sense of efficiency, competitiveness and newness, especially in economic activities. According to Hurun Report Inc. "the average age of Chinese millionaires is 39, whereas in the United States or Europe, the figure is over 50" (China Daily, 2011, p. 16).

\subsubsection{Paradox 7) Long- vs. Short-Term Orientation}

Influenced by the Yin Yang thinking, Chinese culture has traditionally been both long- and short-term oriented. This paradox ha been further accentuated by globalization. A major bone of contention between the partners to a 
Sino-foreign joint venture often relates to this dimension. In the past, when a joint venture first made a profit, the Western partner usually wanted to re-invest that profit in the company, whereas the Chinese party wanted to cash out the profits. Nowadays, on the other hand, Chinese firms are increasingly willing to re-invest for long-term success. This has become a driving force in the increasing internationalization of Chinese companies (Faure \& Fang, 2008).

\subsubsection{Paradox 8) Tradition vs. Modernity}

In today's Chinese society, modern and traditional values and practices coexist. On the one hand, China's recent successful transformation depends upon its effective utilization of foreign direct investment (FDI), new technology and professional management. Hence, people now tend rely on modern approaches and the “scientific development concept" (科学发展观 kexue fazhanguan) is advocated by China's leadership. (Fang, 2014).

The paradoxes above show China to be highly complicated society, attitudes and behaviors develop along a continuum, and it seems that they are never at either extreme but somewhere in between depending on the circumstances. Some professionals, Chinese and foreign, have ever mentioned that the only area available to business in China is the grey area. This area seems to be grey for both local and foreign. What can be especially frustrating when facing conflicting situations with Chinese people at work is that they disagree about what is important to discuss and how they are to approach and deal with their issues. Irritations depend upon people's aspirations, expectations and beliefs, which in turn are based upon their cultural background, as well as their individual personalities. (Tjosvold, Hui, \& Law, 1998). As we will learn in the course of this investigation, China is formed by several sub-cultures coexisting under the same umbrella, but under certain circumstances they following different agendas.

The literature presented above, however brief, depicts the clear picture of an environment that requires high adaptive capability, high tolerance for uncertainty as well as the acquisition of knowledge and building of relationships that require both personal and professional skills. China is perhaps the most competitive society in modern life as well as the most conforming to social norms; this mixture of characteristics creates a puzzle, which elements are important to understand. In order to further enhance that understanding of the elements creating the puzzle forming the Chinese society, I include below an interview with an expert in Chinese organizational culture, Porfessor RongYao Chen, who explains the origins of Chinese people's attitudes and behaviors.

\section{Interview with Porf. Rongyao Chen}

In order to obtain a better understanding of Chinese behavior, it is important to observe what contemporary Chinese experts said about it and how they explain the Chinese organizational reality. In that sense, I interview Porf. Rongyao Chen, expert in Chinese organizational culture and organizational development. Porf. Chen suggests that to understand a society, the outsider must first understand the basic pillars sustaining the construction of attitudes and behaviors within that society. To start, he lists three important aspects common to all Chinese people across ethnic groups.

\subsection{Historical Perspective}

\subsubsection{Long Period of Pedigree Culture, Characterized by a State Run by Agricultural Civilization}

In a pedigree culture, the number of statuses multiplies, population size increases, cities appear, new institutions emerge, social classes arise, political and economic inequality becomes inbuilt into the social structure and culture becomes much more diversified and heterogeneous. But in agricultural societies, unity among family members (the in-groups) is crucial for survival, and those groups compete against each other to protect their families or in-groups. Hence, early in the development of Chinese society togetherness (within in-groups) and separation (society at large) start to exist.

\subsubsection{Long Period of Feudalism}

According to Prof. RongYao Chen, China entered feudalism 1000 years earlier, and ended 200 years after Western Europe. The dictatorship period was very long; therefore, dictatorship became a basic feature of Chinese society. The dominant social system in this kind of societies, such as medieval Europe, resides in the nobility holding lands from the Crown in exchange for military service, and where vassals were tenants of the nobles, while the peasants (villains or serfs) were obliged to live on their lord's land and give him homage, labor, and a share of everything produced in exchange for military protection. This sense of dependency on others for protection led the Chinese to develop the urge and skills to develop strategically relationships. By implication, those relationships were not based on loyalty or friendliness but on exchange of services and/or goods necessary to survive. In order to 
develop those relationships, people should compromise personal interests; therein lays conformity to social rules imposed by those in powerful positions.

\subsubsection{Precocious Characteristics}

Prof. Rongyao Chen, mentions that before science developed and logical analytical thinking took form, Chinese people had all kinds of economic and social problems to be addressed and resolved. Given the lack of a system to deal with those problems, they relayed on a sort of "sudden enlightenment", which later became their basic logical thinking. However unsystematic, people in early Chinese societies, and nowadays, were and are able to overcome difficulties and solve problems in ways that, to the western mind, require specific methodologies. Systematic approach to problems never developed as necessary for survival in the Chinese mind; rather, they developed a thinking process focused on the use of existing resources to solve problems at hand. The focused was on solving the problem at the moment, not on preventing or avoiding recurrence.

This investigator refers "precocious characteristic" as to "circumstantially-activated motivation". Chinese people are use to solve problems without much thinking on sustainable solutions; if the problem reappears, a common phenomenon in Chinese society, they would use different approaches to solve it; their new approach would depend on the circumstances.

\subsection{China from a Social Perspective}

According to Prof. Chen, from a social point of view, Chinese society seems to be built upon a mix of four main pillars including group's cohesiveness, farmer's life, epiphany thinking and despotism.

\subsubsection{Group's Cohesiveness}

This lifestyle is related to agricultural civilizations where families must irrigate relying on collaborative groups. Mutual dependency as well as conformity to group's norms developed at this stage.

\subsubsection{Farmers Life}

In agricultural societies, each family must manage resources to ensure that all its members receive the necessary means for survival. I have spoken above of the collective aspect of this kind of societies. The same as cohesiveness with members of the in-groups strengthen thanks to mutual dependency and support, so separation of the individual from the larger society emerges. Within the larger community, Chinese people distinguish between in-group members, with whom they develop mutuality in almost every aspect of life, and out-groups people, against whom they compete.

Chinese people should use quick thinking regarding the use of their resources and strategic relationships to succeed. In the early stages of Chinese society, and perhaps at present, they arrange life following a peasant-style wisdom, which supports that people should remain free of outside control by owning and managing a variety of resources, and free of debt by running a self-supporting household (Williams, 2008). As capitalism increases in China, peasant wisdom as a practice of life has almost vanished in most of its developed cities such as Shanghai and Beijing, but the mentality of controlling own resources may still dwell deep in people's mind, which may explain why most Chinese people are interested in becoming business owners. Besides, this tendency may explain why in China laws in regulations are accepted in public (social conformity and face-orientation) but ignored in private (peasant wisdom).

\subsubsection{Epiphany Thinking}

The same as the, so-called, precocious characteristic of Chinese society (2.3.1.3 above) In the absence of a system, Chinese people recur to the believe that any needed moment a sort of enlightenment will dawn upon them and help them to go through all difficulties. Traditional unsystematic approaches to problems, through which they have solved many calamities along their history, tell them that this approach is useful to keep moving forward.

\subsubsection{Despotism}

Farmers need the emperor to exert control upon how society should work. Because competition and protectionism from other groups makes it difficult to define a fair way of life, authority became very important in Chinese society. Part of protecting one's resources is to have a powerful entity interfering when problems arise and cannot be solved by mutual agreement between the parties in conflict. But the authority alone wouldn't do much; strategic relations and conformity become even more important here. In order to keep their autonomy, the Chinese will strive for developing strong "family-like" bonds with governing bodies through conformity and face-giving. 


\subsection{China from a Cultural Perspective}

As Prof. Chen explains, there are four cultural characteristics of Chinese people including 1) Group Spirit and Individualism (the paradox that is central to this paper), 2) Practical Wisdom, 3) Unorganized freedom or slackness and 4) Imitation; each of these aspects is explained below. Together with the four pillars mention above (3.3.2), these four cultural characteristics add to the complexity of Chinese society.

\subsubsection{Group Spirit and Individualism}

Herd behavior was extremely strong in early stages of development of the Chinese society. This behavior was instrumental to developing the family-centered culture that is characteristics of Chinese society, and it seems that due to this family-centered aspect, fierce competition among close groups also developed. The Chinese person becomes protective and protected by in-group members and competes for scarce resources against other groups.

Family members will support each other, and they will compromise personal interests and wants without argument since the individual's survival depends on the support of the family. In collectivistic terms, the family or in-group is as collectivistic as China can get. Out of the family (or the in-group) Chinese people becomes individualistic. The wider society is something like the battlefield, where everybody else is an enemy fighting to get as much as possible of the limited available resources. So, in the wider society, individualism is the norm.

Another aspect of Chinese society that confuses the outsider is their ability to ignore others. Public behavior all over China seems to be the same. "To the outsiders, the Chinese have no eyes and no ears". This expression explains with much accuracy Chinese people's attitude and behavior in the wider society nowadays.

\subsubsection{Practical-Wisdom Perspective}

China is a pragmatic society; in a broader sense, emotions are not allowed when it comes to solving any kinds of difficulties, including emotional issues. Hence, Chinese people are very strong at solving problems in a practical manner, and they easily rise during difficult times.

As compared to most westerners, as I have observed for the last twenty years, Chinese people at work and elsewhere seem to be less dramatic regarding limitations. Facing a problem, regardless of the nature of the problem, the western individual seems to look for solutions and preconceived standards and procedures. In the absence of a system, westerners show to be stressful, while Chinese will take whatever available resources and options there are, and used solve the issues at hand.

Prof. Chen expresses that one salient characteristic of modern society in China is that Chinese people don't have the concept of limit. This Chinese attitude has to sides. On the positive side it allows them to move forward regardless the obstacles; it seems that there is no much thought process regarding the effects of their actions, they act first and think later. If things don't work, they keep trying until they reach their target. On the negative side, such tendency to act with no much thought may lead to damaging the environment or their fellow citizens since what moves them are personal or in-group goals, hence they move with disregard for those who are part of their in-groups.

Observations at business organizations indicate that, good performance in China may be evaluated based the ability of the employee to solve rather than to prevent problems. A common expression from leadership in Chinese working environments is "let's do it first and we'll talk about it later", while for the western mind, there should be a thought process before acting.

\subsubsection{Unorganized Freedom or Slackness}

Chinese people recognize the importance of having a leader, but at the same time reboot that value, exhibiting a lack of awareness of the rules. Because survival of the individual or in-group members is perceived to be at stake, peasant wisdom reminds leading the Chinese behavior. It seems that rules and laws exist to deal with problems, when person-to-person or group-to-group direct negotiations are unsuccessful, rather than to lead individual's behavior or prevent social turmoil; conformity and compromising for the sake of maintaining strategic relationships takes care of it.

\subsubsection{Imitate}

When Prof. Chen speaks of the tendency to imitation in China, he speaks of the anxiety for rapid imitation, which he sees obvious traces of feudalism. Other aspects such as being face-oriented may also influence this aspect since socials approval is where the Chinese find "face", and in feudal societies what society approves is what the leadership states as correct or acceptable. In this sense, social conformity seems to take the form or imitation. In order to ovoid loosing face, people would tent to imitate what is socially accepted rather than create something new. Chinese people's tendency to imitate is also related to behavior based on what that behavior tells 
about the person as a member of society. Conformity in China, means not only acceptance of group norms, but sameness acquired by imitation.

Given the high importance placed to social approval, the Chinese culture is characterized by seeking the sameness, similar within inner circles, imitating those socially empowered networking. Chinese people value relationships, rapid cloning, disapproval of difference, and network survival.

The visitor is advised to be aware and know these cultural characteristics since it would make it easier for him or her to develop and manage interactions with Chinese people. The secret in getting along with the Chinese and hence achieving the expected goals, one has to find ways to be accepted as one of the in-group members. Conforming and assimilating or practice similarity with the Chinese may help. What aspects are there to imitate is not pertinent to this discussion, and will necessarily depend upon the cultural background of the visitor.

\subsection{China from a Multicultural-Country Perspective}

Prof. Chen, expresses that China is a country made up by different cultural groups that interact in a daily basis under the same "China umbrella", but that regardless the similarities stated above, they remain different and apart from each other; their motivations are different. There is Bohai Bay Confucian culture, Taoist culture in Jiangsu and Zhejiang region, which is based on action according to circumstances, and the Hakka culture of Pearl River at the Delta region to mention just a few. These cultures are a mixture of several features including openness to learning new methods and implement technologies, hard work, innovation, inclusiveness (group oriented), tireless, courageous, practice and the mentality of "as the battle progresses one's courage amounts".

\subsubsection{Regional Sameness}

To illustrate Prof. Chen's points regarding the different subcultures forming China as a country, the list below shows some salient characteristics that apply to Chinese people from different cities including Beijing, Shanghai, Guangzhou/Shenzhen and select cities in Western China (Tung, Worm, \& Fang, 2008: 63).

- Beijing (capital city, center of political power in the country):

Politically-oriented — everyone talks about politics.

Bureaucratic — given the prevalence of state-owned enterprises (SOE's) in Beijing and surrounding areas, people tend to be more bureaucratic.

Emphasis on integrity - people place more emphasis on personal trust in business dealings.

Highly educated — many of the bureaucrats are highly educated.

More relationship-focused.

More fluid perception of time.

Face comparatively more important.

More holistic in approaching issues.

Focus on general principles.

More diversified cultural life.

More direct and straightforward

\section{- Shanghai-Economic center of China}

Less straight forward, Shanghainese tend to argue over trivial matters.

Confident and arrogant - because Shanghai has been an important economic center and is the trendsetter in fashion, Shanghainese tend to look down upon people from other cities, referring to them as "villagers".

Materialistic - Shanghainese are more concerned with brand names.

More tactical, i.e., calculating.

Greater admiration of the West.

More younger people who have attained high positions.

Obsessed with career progression

\section{- Guangzhou/Shenzhen (southern city close to Hong Kong):}

Hard working and highly efficient - one excellent example is building of a 30-floors skyscraper in fifteen days in Hunan Province. 
Larger concentration of mass assembly manufacturing.

Entrepreneurial - many prefer to start up their own businesses as opposed to working for established corporations.

Pride in cuisine and more exotic cuisine.

Greater deviation from the norm.

Less concerned about politics.

Identify more closely with Hong Kong.

More concerned with work-life balance issues.

Superstitious - large entrepreneurship, they tend to be more superstitious.

More informal in protocol and clothing.

More risk taking

- Western China (cities like Chongqing and Chengdu):

More conservative.

More clannish.

More traditional.

Particularistic - emphasize knowing your counterpart first before doing business.

Socializing (eating, drinking, and smoking) is very important.

Greater emphasis on personal relations, i.e., rely on people more than laws or negotiations.

Less experience with international business.

More laid back.

More hardy.

More emotional.

In general, westerners find it more difficult to negotiate/do business here.

\subsection{The History behind the Success of Chinese Revolutions}

Porf. Rongyao Chen, explains that China has undergone three revolutions, the cultural revolution of Mao Zedong, the economic revolution of Den Xiaoping, and the ongoing structural revolution of Xi Jinping. For these revolutions to succeed, the leaders need a society that follows as a whole since social divisions would make it difficult to implement the policies corresponding to each revolution. Hence, several aspects along the history of China development had to remain the same; those aspects are:

1). The offer of a material gaining in exchange for conformity. For example, Mao Zedong used land to attract farmers to become militants of the communist party.

2). Implant in people's mind the social rules to which they should conform through formal and informal education. The most important ones continue to be the Three Rules of Discipline and Eight Warnings.

The Three Rules of Discipline set the basis for the Chinese in-group attitudes and behavior.

$3)$. Follow without questioning. This rule encourages people to follow the leader without questioning.

4). Don't steal even a straw or needle. This rule is self-explanatory.

5). Give the leader all goods recovered from the war. In modern times, where the battle is for market share, this translates into passing all profits to the organization for the leaders to distribute among all accordingly with their performance.

\subsection{Eight Pillars of Chinese Behavior}

The Eight Warnings set Chinese people's public attitudes and behavior below are self explanatory and represent the pillars sustaining attitudes and behavior of Chinese people.

a) Speak gently to others.

b) Trade fairly.

c) Return what you borrowed. 
d) Pay for whatever you brake.

e) Don't fight or insult others.

f) Don't destroy others' crops.

g) Don't flirt with other's wife.

h) Don't hurt or kill your captured enemies.

Many observable aspects of modern Chinese society seem to contradict the above rules and warnings; however, those eight warnings are observed in closed circles. It is important to keep in mind that Chinese people is passive, adaptive and observe reciprocity when interacting with their in-group members, but may be the opposite when interacting with outsiders. This switch of behavior is what confuses the western visitors since we do not have much access to the inner circles to the extent that we can experience or observe these eight warnings in practice.

\subsection{Chinese Organizational Culture}

For organizational culture to function as the foundation to economic effectiveness, three elements are necessary: First, a unified economic power, which enhances the effect of the group on the individual and leads to building the basic characteristics of groups' operations. Second, a profit-oriented logic, which is based on competition for profit among units that act as small independent companies within the organization; having access to the company's limited resources, they compete to meet economic targets, which in turn will deliver higher economic earnings for the team and each individual in it. Third, economic-oriented structure where personal and organizational goals should be the same so that all resources are directed towards a single goal namely the economic growth of the organization. These are organizational characteristics thought of as being Chinese, but in general, organizations in Eastern cultures, which are collectivistic and high-context in nature, operate following more or less the same principles. Below is a summary of the Chinese organizational culture.

1)- They draw a pie by setting targets, and later share the whole pie with everybody in the organization, the size of the slice each member gets depends on group and individual performance. Mutual dependency and conformity for the sake of survival becomes clear especially in business organizations. Team members will quickly adapt to team norms regardless of their personal opinions or interests.

2)- They establish a mechanism for fare competition. Basically this mechanism refers to providing resources, which every group can take and use in order to meet their targets. Governance or leadership allows all its members to have access to all available resources. The most competitive team would be able to use those resources better or to maximize the amount available for them. Competitiveness within the organization is important in order to gain resources.

3)- They implement benevolent authoritarian management style, guided by social integration to encourage goals achievement. Such management style is known as paternalistic, where the leader is the father figure, and sole decision maker, who protects and supplies for his children (the employees) in exchange for obedience and loyalty. The element of conformity is stressed in terms of social integration where the group's are more important than the individual's interests.

Chinese business organizations reflects not only fundamental family values of the staff, it reflects the center of the individual's life because it provides all the necessary resources for individual growth. I should emphasize that in terms of professional growth and career opportunity in China, the person has not much voice regarding his or her own value as a member of society; is the society, and mainly the leader figures in that society who ultimately set an individual's value. A business organization in China can be describe as follows:

a- The enterprise is like home - entering the business organization is like entering a home.

b- The enterprise is like school - the employee can learn and grow at "this" school.

c- The enterprise is a platform - where the employees can perform and achieve self-worth.

d- The enterprise is an expectation - employees rely on companies achieve their goals

e- The enterprise is the future - business development, provide a future for the employees.

Looking at the aspects above, we can say that the economic success of Chinese people along their history is basically the success of this cultural forms and structures.

\section{Methodology to Scientific Approach}

In order to understand difference in mentality between Chinese and non-Chinese professionals, a questionnaire listing several aspects affecting people's interaction was sent to seventy Chinese and seventy non-Chinese 
professionals working in Shanghai, Guangzhou, Hangzhou and Beijing in different fields including international trade, sourcing, logistics, compliance, quality control, supply chain consultancy, diplomacy and education. Respondents were presented with twenty-six aspects, divided in three categories, seemingly affecting cross-cultural interactions at work including Attitude (determined by values): Friendliness, being active and positive, responsibility, good demeanor, sociability, willingness to learn, flexibility, sense of humor and being humble; Education and skills (determined by school education systems): Academic background, foreign language capability, mother tong, creativity, school attended, credentials, interests, communication skills, good command of English and intellectual curiosity; and Physical aspects (determined by race and clothing): Age, general appearance, gender, height, skin color, clothing, and health appearance.

Results from the questionnaire were analysis through theoretical frameworks; statistical data, an interview with Porf. RongYao Chen, who explain the findings from the Chinese perspective.

\subsection{Questionnaire Design and Feasibility}

Before sending the questionnaire out for data collection, its design and feasibility were tested with the use of AMOS (See Figure 1). The estimated variance of "p" (Physical aspects) is 3.71 and the one for "es" (Education-skills) is 4.73. The covariance between these two variables is 4.12. This indicates that there is not conflict between the categories. "p" and "es" when tested for dependability against attitude.

Attitude is here assumed to be triggered by the visual stimuli of behavior and form through education (family, school and the wider society), hence covariance between attitude and physical aspects (0.09) and between attitude and Education and Skills (0.79) was tested. Since the unstandardized regression coefficient represents the amount of change in the dependent variable per single unit change in the predictor variable, this result suggests that for every single unit of increase in education/skills and physical aspects, attitude become more salient by .09 and .79 correspondingly. Statistical data in this regard is shown below.

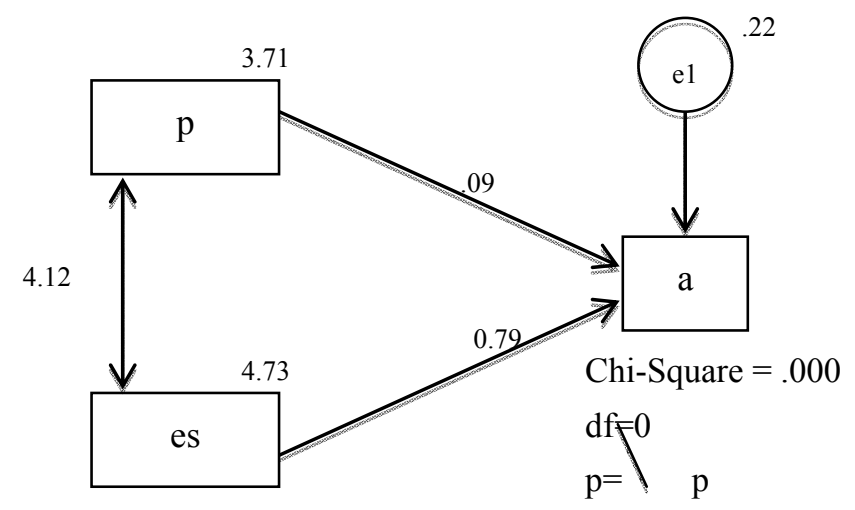

Figure 1. AMOS questionnaire reliability test covariance among the three categories of the final criteria

Table 1. Questionnaire reliability regression weights: (group number 1 - default model)

\begin{tabular}{llllll}
\hline & Estimate & S.E. & C.R. & P & Lable \\
\hline $\mathrm{a}<--\mathrm{p}$ & .09 & .17 & .56 & .58 & Par_1 \\
$\mathrm{A}<-$ es & .79 & .15 & 5.34 & $* * *$ & Par_2 \\
\hline
\end{tabular}

Table 2. Questionnaire reliability standardized regression weights: (group number 1 - default model)

\begin{tabular}{llll}
\hline & & & Estimate \\
\hline $\mathrm{a}$ & $<---$ & $\mathrm{p}$ & .09 \\
$\mathrm{a}$ & $<---$ & es & .88 \\
\hline
\end{tabular}


Table 3. Questionnaire reliability covariance: (group number 1 - default model)

\begin{tabular}{|c|c|c|c|c|c|c|}
\hline & & Estimate & S.E. & C.R. & $\mathrm{P}$ & Label \\
\hline $\mathrm{p}$ & $<-->$ es & 4.12 & .71 & 5.83 & $* * *$ & par_3 \\
\hline
\end{tabular}

Table 4. Questionnaire reliability correlations: (group number 1 - default model)

\begin{tabular}{llll} 
& & Estimate \\
\hline $\mathrm{p}$ & $<-->$ & es & .98 \\
\hline
\end{tabular}

Table 5. Questionnaire reliability variances: (group number 1 - default model)

\begin{tabular}{llllll}
\hline & Estimate & S.E. & C.R. & P & Label \\
\hline $\mathrm{p}$ & 3.71 & .63 & 5.87 & $* * *$ & par_4 \\
es & 4.73 & .80 & 5.87 & $* * *$ & par_5 \\
e1 & .22 & .04 & 5.87 & $* * *$ & par_6 \\
\hline
\end{tabular}

Table 6. Questionnaire reliability squared multiple correlations: (group number 1 - default model)

\begin{tabular}{ll}
\hline & Estimate \\
\hline $\mathrm{a}$ & .94 \\
\hline
\end{tabular}

Table 7. Questionnaire reliability critical ratios for differences between parameters (default model)

\begin{tabular}{lllllll}
\hline & par_1 & par_2 & par_3 & par_4 & par_5 & par_6 \\
\hline par_1 & .00 & & & & & \\
par_2 & 2.22 & .00 & & & & \\
par_3 & 5.54 & 4.61 & .00 & & & \\
par_4 & 5.54 & 4.50 & -3.67 & .00 & & .00 \\
par_5 & 5.64 & 4.81 & 4.46 & 4.12 & -5.60 & .00 \\
par_6 & .73 & -3.76 & -5.51 & -5.52 & & \\
\hline
\end{tabular}

\subsection{Factor Analysis}

In order to acquire further understanding of the data, a factor analysis was carried out to group some characteristics together and plot the result. There are multiple ways to carry out Factor Analysis, here I chose Principal Component Analysis. In the rest of the study I will speak of factors and components in the same way. We analyze the whole data, with both countries, to reduce the overall dimension.

\subsubsection{The KMO and Bartlett's Test}

This test is used to verify if the Principal Component Analysis is meaningful. The Sampling Adequacy is an indicator between 0 and $1 ; 1$ being the ideal outcome (Table 8).

Table 8 . KMO and Bartlett's test sampling adequacy is around 0,8 which is highly satisfactory

\begin{tabular}{lll}
\hline Kaiser-Meyer-Olkin Measure of Sampling Adequacy. &, 799 \\
\hline \multirow{4}{*}{ Bartlett's Test of Sphericity } & Approx. Chi-Square & 3469,534 \\
& df & 325 \\
& Sig. &, 000 \\
\hline
\end{tabular}




\subsubsection{Number of Components}

Table 9. Number of components spss calculation of how many components are necessary to explain the overall variance (at a high percentage)

\begin{tabular}{llll}
\hline \multirow{3}{*}{ Component } & \multicolumn{2}{l}{ Initial Eigenvalues } \\
& Total & \% of Variance & Cumulative \% \\
\hline 1 & 8,968 & 34,492 & 34,492 \\
2 & 3,340 & 12,847 & 47,339 \\
3 & 2,745 & 10,558 & 57,898 \\
4 & 2,050 & 7,885 & 65,783 \\
5 & 1,608 & 6,186 & 71,969 \\
6 & 1,199 & 4,612 & 76,581 \\
\hline
\end{tabular}

It was found out that 6 components are necessary and explain about $77 \%$ of the variance. To improve our next results it is advised to calculate new eigenvalues after rotation of the factor space. The rotation has for effect to redistribute the percentage of variance more equally between the components (Table 10).

Table 10. Eigenvalues after rotation

\begin{tabular}{llll}
\hline & \multicolumn{2}{l}{ Rotation Sums of Squared Loadings } \\
Component & Total & 18,116 & Cof Variance \\
\hline 1 & 4,710 & 17,317 & 18,116 \\
2 & 4,502 & 15,527 & 35,433 \\
3 & 4,037 & 11,811 & 50,960 \\
4 & 3,071 & 7,634 & 62,770 \\
5 & 1,985 & 6,176 & 70,405 \\
6 & 1,606 & & 76,581 \\
\hline
\end{tabular}

\subsubsection{Component Matrix}

Component matrix shows the link between the survey variables and the components. Table 11 shows the matrix after rotation. Rotation converged in six interactions.

Table 11. Rotated component matrix extraction method: principal component analysis rotation method: varimax with kaiser normalization

\begin{tabular}{|c|c|c|c|c|c|c|}
\hline & \multicolumn{6}{|c|}{ Component } \\
\hline & 1 & 2 & 3 & 4 & 5 & 6 \\
\hline Willingness to Learn & 844 & & & & & \\
\hline Clothing & ,798 & & & & & \\
\hline Good Demeanor & ,775 & & & & & \\
\hline Health &, 725 & & &, 300 & & \\
\hline Mother Tongue &, 715 & ,368 & & & & \\
\hline Age & ,696 & & & & & \\
\hline Credentials & ,661 & & & ,461 & & \\
\hline Appearance & &, 864 & & & & \\
\hline Positive & &, 842 & & & & \\
\hline Interests & &, 841 & & & & \\
\hline Gender & &, 808 & & & & \\
\hline Creativity & &, 770 & & &,- 309 & \\
\hline Flexibility & & & ,951 & & & \\
\hline English & & & ,940 & & & \\
\hline Sociability & & & ,936 & & & \\
\hline Education Quality & & & 877 & & & \\
\hline
\end{tabular}




\begin{tabular}{|c|c|c|c|c|c|c|}
\hline Friendliness & & & & ,796 & & \\
\hline Curiosity & & & ,335 & ,653 & & \\
\hline Language & & & &, 592 &,- 375 & \\
\hline Academic background & & ,396 & &, 530 & & \\
\hline Communication Skills &, 324 & & &, 507 & &,- 332 \\
\hline Sense of Humor & & & & &, 708 & \\
\hline Skin Color &, 572 & & & &, 592 & ,367 \\
\hline Height & &, 572 & & &, 582 & \\
\hline Humility & & & & & & ,832 \\
\hline Responsibility & ,387 & & & ,425 &,- 316 & ,594 \\
\hline
\end{tabular}

The interpretation of the matrix shows the first component as the following group of variables: Willingness to learn, Clothing, Good Demeanor, Health, Mother Tongue, Age, Credentials. This first component is highly associated with the outward aspect of the person (a part from Credentials, but as we can see this variable is the least important in the component). The following table sums up all the components.

Table 12. Components and variables

\begin{tabular}{ll}
\hline Component & Variables \\
\hline 1 & Willingness to learn, Clothing, Good Demeanor, Health, Mother Tongue, Age, Credentials \\
2 & Appearance, Positivity, Interests, Gender, Creativity \\
3 & Flexibility, English Fluency, Sociability, Quality of Education \\
4 & Friendliness, Curiosity, Language, Communication skills, Academic Background \\
5 & Sense of Humor, Height, Color of Skin \\
6 & Being humble, Responsibility \\
\hline
\end{tabular}

\section{Results and Discussion}

As expected, there is a big difference between the Chinese and the non-Chinese groups of respondents regarding what matters for international cooperation. Besides, the Chinese professionals show to be dispersed, showing little or no agreement regarding what is important to establish the cooperation discussed in this investigation. To the reader with no experience living in China, the separation shown within the Chinese sample may seem unexpected and may represent a paradox since Chinese people (and Asian people in general) are known as moving together, and in fact, we can see this to be the case anywhere in the world, Chinese people settle close to other Chinese people, as a group they progress together. As a collectivistic culture, hence conforming to group norms, they may be expected to have a unified mindset. On the contrary, non-Chinese societies are said to be individualistic, they focus on the individual and do not conform to group norms. Different mindsets among the non-Chinese professionals would be expected. Results however, show a different picture. Let's see these differences in a graphical manner.

\subsection{Graphical Interpretation of Components-Factors Relationship-Scatter-Plots Matrix}

To illustrate the divergence between, and within, the two groups of respondents clearer, I present scatter-plots matrixes with all 6 factors below. 


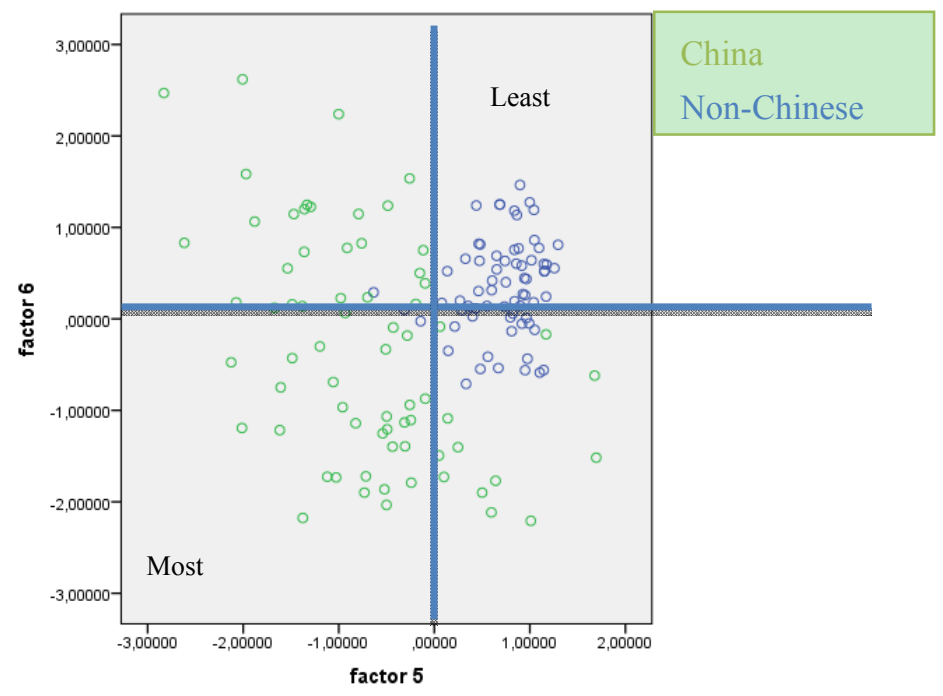

Figure 2. Relationship of factors $5^{\text {th }}$ and $6^{\text {th }}$

There is a clear separation within the Chinese group (green dots), while the non-Chinese group (blue dots) seems to be more cohesive in regard to both factors. As a group, the Chinese sample show no agreement in regard to the importance of either factor; while the non-Chinese group seems to give less important to both factors 5 and 6 .

Table 13. Components and variables for factors 5 and 6

\begin{tabular}{ll}
\hline Component & Variables \\
\hline 5 & Sense of Humor, Height, Color of Skin \\
6 & Being humble, Responsibility \\
\hline
\end{tabular}

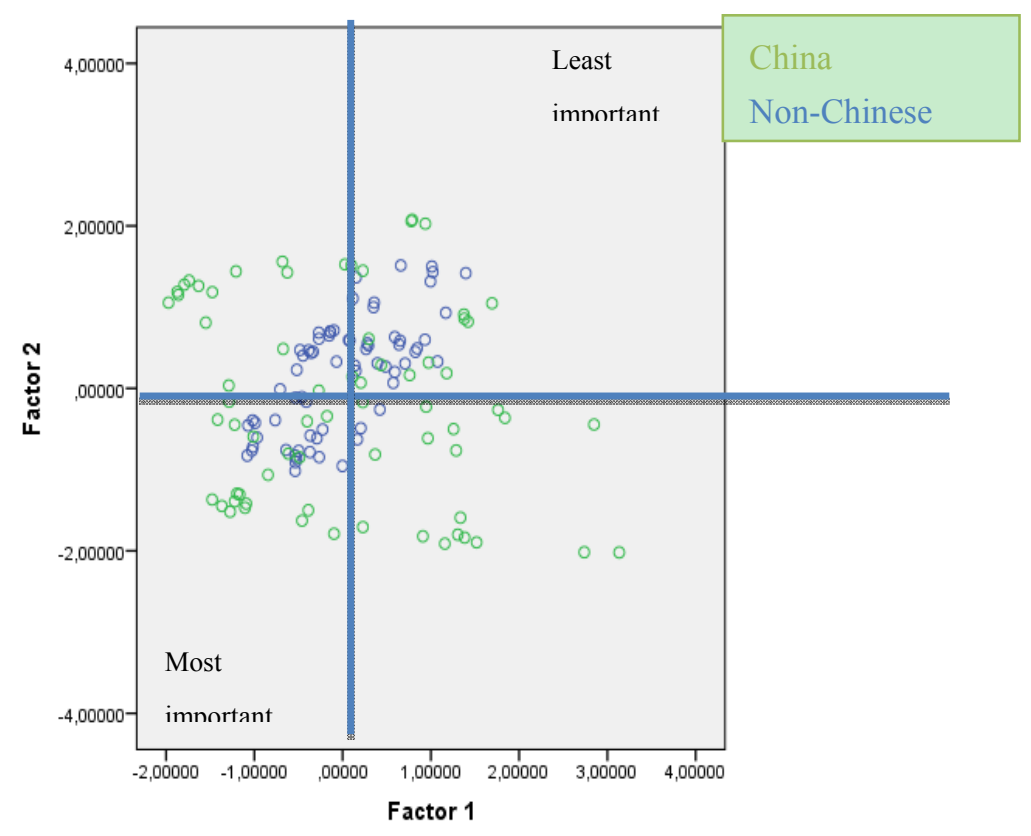

Figure 3. Relationship of factors 1 and 2

In general both groups react positively towards factors 1 and 2. However, the Chinese group of respondents is 
more scattered. Both groups show some unity and dispersion in regard of the importance they attached to the variables within factors 1 and 2 for successful cross-cultural interactions.

Table 14. Components and variables for factors 1 and 2

\begin{tabular}{ll}
\hline Component & Variables \\
\hline 1 & Willingness to learn, Clothing, Good Demeanor, Health, Mother Tongue, Age, Credentials \\
2 & Appearance, Positivity, Interests, Gender, Creativity \\
\hline
\end{tabular}

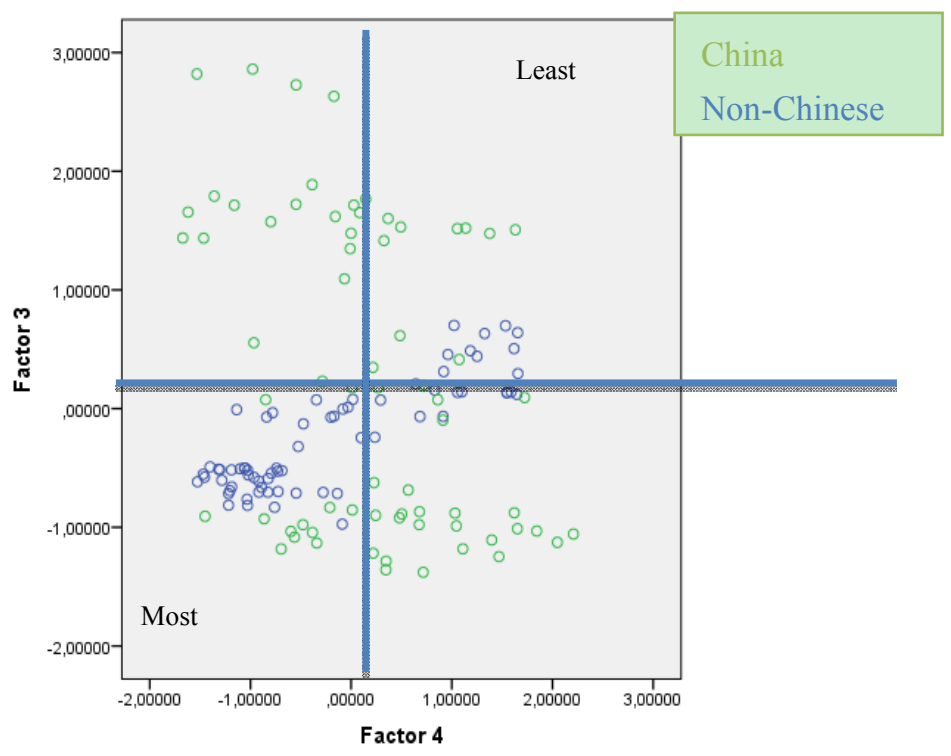

Figure 4. Relationship between factors 3 and 4

Seemingly more Chinese respondents agree on the importance of variables in factor 3, but as a group they are more scattered than the non-Chinese respondents. It seems like more respondents in the non-Chinese group of respondents give high importance to the variables within both factors.

Table 15. Components and variables for factors 3 and 4

\begin{tabular}{ll}
\hline Component & Variables \\
3 & Flexibility, English Fluency, Sociability, Quality of Education \\
4 & Friendliness, Curiosity, Language, Communication skills, Academic background \\
\hline
\end{tabular}




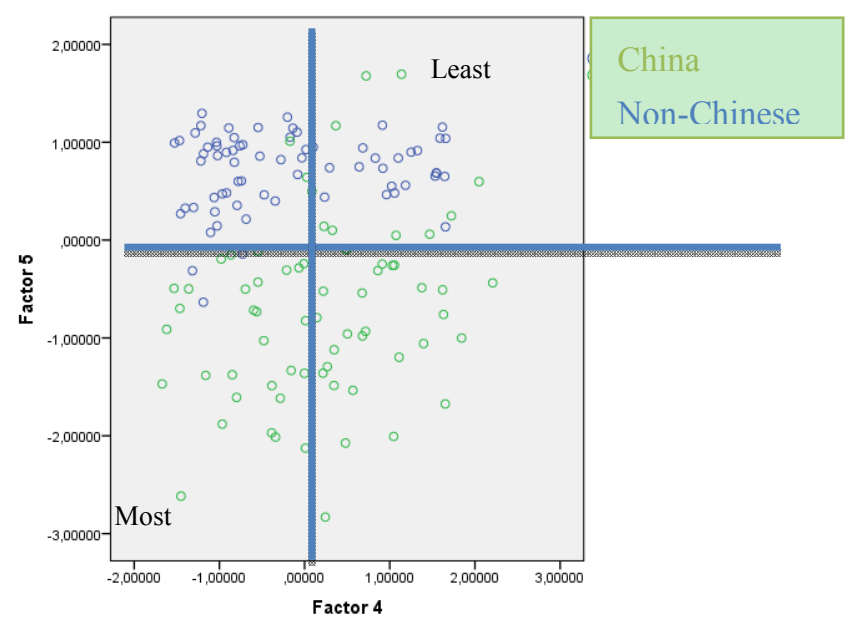

Figure 5. Relationship between factors 4 and 5

The separation of the Chinese respondents is also very clear on this figure. In fact, we may say that in regard with factors 5 and four, members of the Chinese group show not agreement at all. Another clear aspect is the opposite direction between the two groups of respondents. In general, non-Chinese respondents give less importance to variables within factor 4 and seem to be divided in regard to factor 5 , still they remain cohesive as compared to their counter part; Chinese respondents are scatters along the continuums within both factors.

Table 16. Components and variables for factors 4 and 5

\begin{tabular}{ll}
\hline Component & Variables \\
\hline 4 & Friendliness, Curiosity, Language, Communication skills, Academic Background \\
5 & Sense of Humor, Height, Color of Skin \\
\hline
\end{tabular}

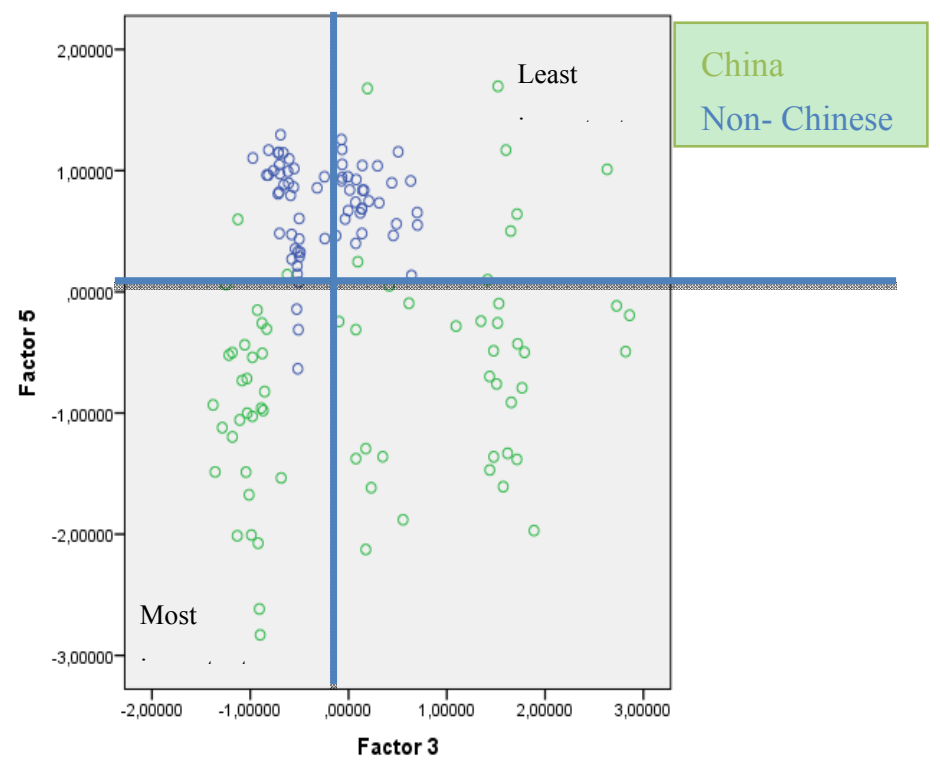

Figure 6. Relationship between factors 3 and 5

The separation of the Chinese respondents continues to be very clear on this figure specially regarding variables within factor 5. Both groups seem to be opposite to each other especially in regard to factor 5 . Regardless the 
in-group's division, non-Chinese respondents show more cohesiveness than Chinese respondents.

Table 17. Components and variables for factors 3 and 5

\begin{tabular}{ll}
\hline Component & Variables \\
\hline 3 & Flexibility, English Fluency, Sociability, Quality of Education \\
5 & Sense of Humor, Height, Color of Skin \\
\hline
\end{tabular}

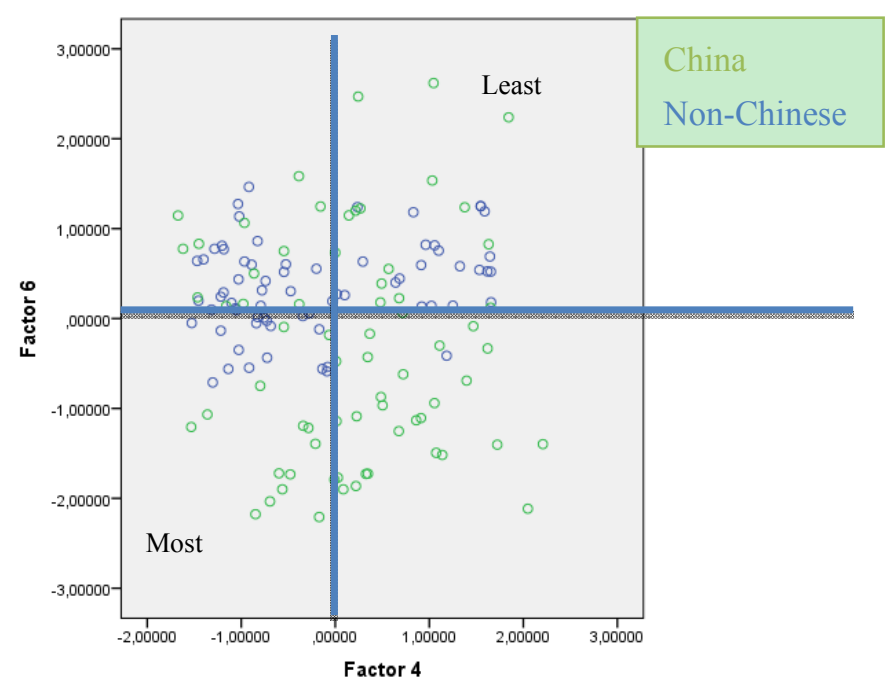

Figure 7. Relationship between factors 4 and 6

Both groups are dispersed in regard with these two factors. We have seen the non-Chinese separation regarding factor 4 on Figure 4. An explanation to this is the fact that most variables refer to very personal aspects and are also less prone to change. Figure 7 (above) also shows most non-Chinese respondents giving less importance to both factors as compared to Chinese respondents, which show a wider dispersion as to how important both factors are.

Table 18. Components and variables for factors 4 and 6

\begin{tabular}{ll}
\hline Component & Variables \\
\hline 4 & Friendliness, Curiosity, Language, Communication skills, Academic background \\
6 & Being humble, Responsibility \\
\hline
\end{tabular}




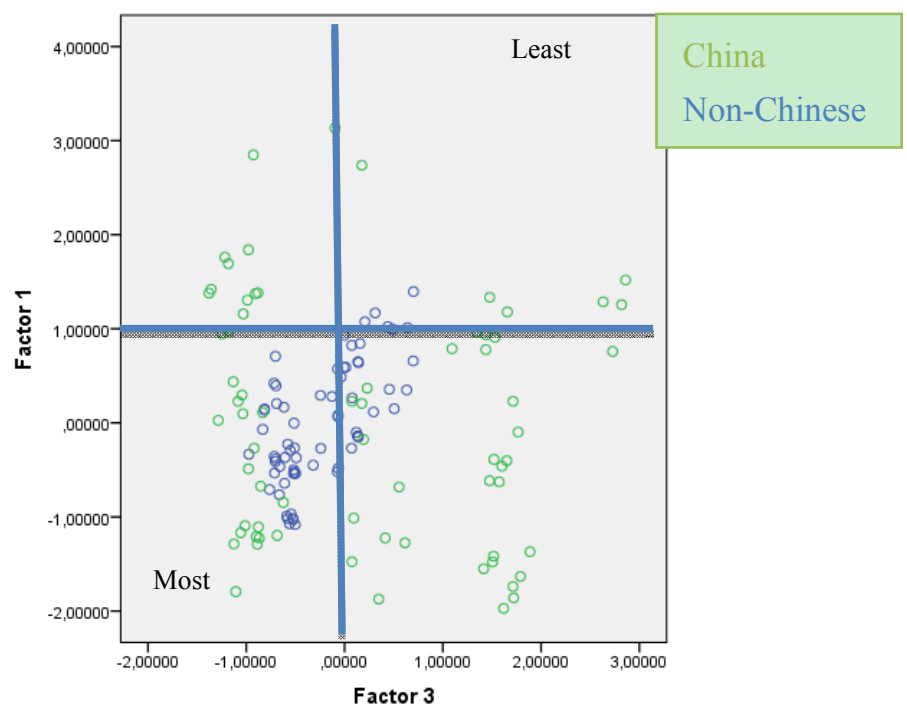

Figure 8. Relationship between factors 1 and 3

The tendency is towards these two factors being important or somehow important (we see a concentration of the population towards zero). Here again the separation among Chinese respondents remains evident.

Table 19. Components and variables for factors 1 and 3

\begin{tabular}{ll}
\hline Component & Variables \\
\hline 1 & Willingness to learn, Clothing, Good Demeanor, Health, Mother Tongue, Age, Credentials \\
3 & Flexibility, English Fluency, Sociability, Quality of Education \\
\hline
\end{tabular}

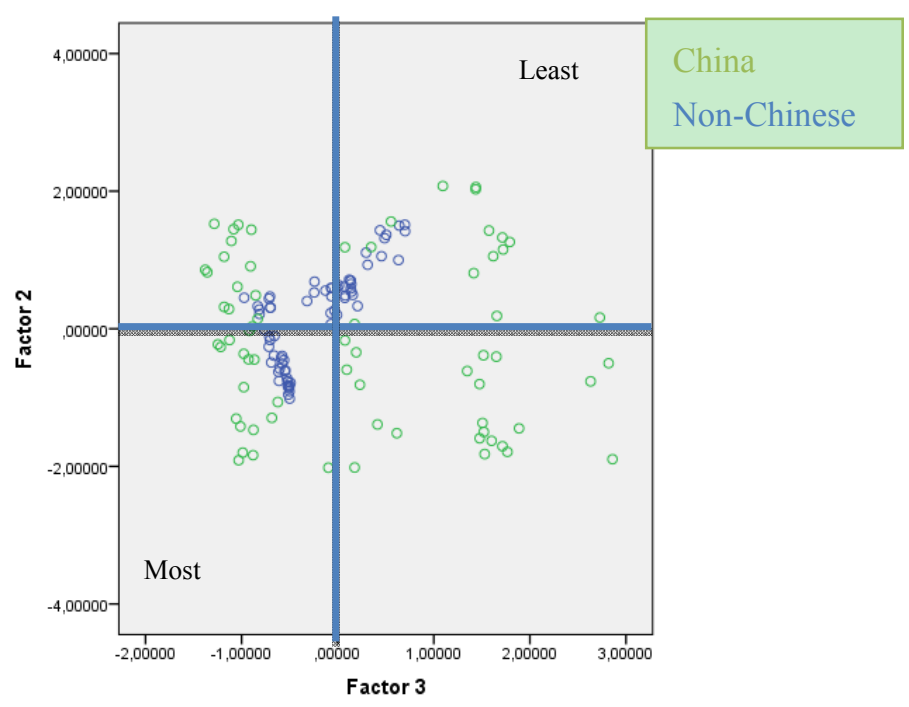

Figure 9. Relationship between factors 2 and 3

Both groups show a central tendency regarding factor 2, but show difference regarding the importance they give to variables within factor 3 ; both groups seem to be divided in this regard with the Chinese respondents being more scattered than the non-Chinese respondents. 
Table 20. Components and variables for factors 2 and 3

\begin{tabular}{ll}
\hline Component & Variables \\
\hline 2 & Appearance, Positivity, Interests, Gender, Creativity \\
3 & Flexibility, English Fluency, Sociability, Quality of Education \\
\hline
\end{tabular}

The findings in this investigation show that the Chinese group of respondents is not cohesive. From the theoretical framework as well as from the interview with Prof. Chen regarding the cultural diversity and forces building the Chinese mentality, we learned that Chinese society is built up of in-groups (sort of clans), the society outside those in-groups does not require agreement among its members. This may be the reason why we such evident separation among the Chinese respondents that contributed to this investigation. This sample includes people that don't belong to the same in-groups. The cultural diversity within China, widely represented in Shanghai, may also explain the separation among the Chinese respondents.

How then do we explain the seemingly togetherness we observe everywhere there is a Chinese community? The answer to this question may be as follows: Chinese people understand that networking is key to survival. From their early agricultural history, they witness individual progress by networking with people who may posses complementary resources for survival, they build close relationships with those complementary forces, forming groups that extend to what is necessary. Outside those groups, everybody else is a competitor. So, the togetherness we observe within Chinese communities is for the survival of the individual and those in his or her inner circles. In the larger society, the Chinese person stands alone. Especially in modern Shanghai, we will very seldom see members of the same in-group making a population large enough to produce results that show agreement.

The cohesiveness of Non-Chinese respondents can be explained by the fact that they grew up in society with fixed rules and regulations that set, or enforce, what people should do and how they should behave in different situations. Their mentality regarding what is important or not is learnt through those rules. Western societies learn "the proper" way through written laws, while in China, social rules are acquired mainly through tacit i-group's agreements. Social rules and laws in most of the western world have been spread internationally through conquering, religion, philosophy, history and mass media among others, so most western countries, regardless of their local particularities, may hold similar values and principles, which in turn leads to similar mindsets regarding what is important for work and social interactions.

It is important to mention that, however the separation and cohesiveness shown in this investigation seem accurate, they may prove wrong if the variables under study were different.

\section{Implications to International Cooperation}

The differences unveiled and presented in this investigation, represent a source of conflict between Chinese and non-Chinese professionals when cooperation is intended. The results of this investigation present the reader with the opportunity to foresee where conflict may arise and prepare in advance as well as with the opportunity to identify the aspects that may be causing conflict in existing cooperation. Here, both Chinese and non-Chinese people have the source to list what either side considers important, which is key to allow for cooperation as well as influence willingness to engage in conflict resolution processes.

In looking for mutual benefits, foreigners working in China are advised to develop social bonds with Chinese nationals through social gatherings first, and allowed some room for "invasion" to privacy, since Chinese people need to know others to a certain personal level before the commit. This tendency exist due to the in-groups constant competition for scarce resource and the commitment that exist to look for the wellbeing of all those belonging to the in-groups. Outsiders are left off and unsupported.

An understanding of the sub-cultural background of Chinese people with whom a foreigner interacts is strongly advised since it would help to build up a behavioral and attitudinal framework for more successful interaction with Chinese partners. Understanding what matters for Chinese people in regard to establishing international cooperation is key, since such understanding may lower the stress level caused by what otherwise would seem incoherent or unimportant to the non-Chinese person. Conflict will arise anyway, but knowledge of the facts causing that conflict allows for willingness to engage in conflict resolution processes, which in turn may enhance organizational stability and growth. 


\section{References}

Blackman, C. (1997). Negotiating China: Case Studies and Strategies. Allen and Unwin, St. Leonards, NSW, Australia.

Bond, M. H., \& Hofstede, G. (1989). The cash value of Confucian values. Human Systems Management, 8, 195-200.

Cameron, K. S., \& Quinn, R. E. (1999). Designing and changing organizational culture based on the competing values framework. Reading, MA: Addison-Wesley Longman.

Chen, M. (1995). Asian Management Systems: Chinese, Japanese and Korean Styles of Business. London: Routledge.

Chen, M. J., \& Miller, D. (2010). West meets East: Toward an ambicultural approach to management. Academy of Management Perspectives, 24, 17-24. http://dx.doi.org/10.5465/AMP.2010.55206381

Chen, R. Y. (2014). Interview conducted at the Glorious Sun School of Business Administration, Donghua University, Shanghai, China.

Child, J., \& Markóczy, L. (1993). Host-Country Management Behavior and Learning in Chinese and Hungarian Joint Ventures. Journal of Management Studies, 30(4), 611-631. http://dx.doi.org/10.1111/j.1467-6486.1993.tb00318.x

China Luxury. (2007). Retrieved from http://www.hkicpa.org.hk/APLUS/0710/p24_29.pdf

Fang, T. (1999). Chinese Business Negotiating Style. Sage, Thousand Oaks, CA.

Fang, T. (2001). Culture as a Driving Force for Inter firm Adaptation: A Chinese Case. Industrial Marketing management, 30, 51-63. http://dx.doi.org/10.1016/S0019-8501(99)00088-7

Fang, T. (2014). Understanding Chinese culture and communication: The Yin Yang approach. In Bettina Gehrke \& Marie-Therese Claes (Eds.), Global Leadership Practices (pp. 171-187). London: Palgrave Macmillan.

Fang, T., \& Fure, G. O. (2010). Chinese communication characteristics: A Yin Yang perspective. International Journal of Intercultural Relations.

Fang, T., Zhao, S., \& Worm, V. (2008). Editorial: The changing Chinese culture and business behaviour. International Business Review, 17(2), 141-145. http://dx.doi.org/10.1016/j.ibusrev.2008.02.010

Faure, G. O., \& Fang, T. (2008). Changing Chinese values: Keeping up with paradoxes. International Business Review, 17(2), 194-207. http://dx.doi.org/10.1016/j.ibusrev.2008.02.011

Gao, G., \& Ting-Toomey, S. (1998). Communicating effectively with the Chinese. Thousand Oaks: Sage.

Gao, G., Ting-Toomey, S., \& Gudykunst, W. B. (1996). Chinese communication processes. In M. H. Bond (Ed.), Thehandbook of Chinese psychology (pp. 280-293). Hong Kong: Oxford University Press.

Hofstede, G. (2001). Cultures Consequences (2nd ed.). Sage Publication Inc.

Hofstede, G. (2003). Cultures and Organizations. Intercultural Cooperation and its Importance for Survival. Software of the mind. Profile Books Ltd.

Leung, K. (2008). Chinese culture, modernization, and international business. International Business Review, 17, 184-187. http://dx.doi.org/10.1016/j.ibusrev.2008.02.009

Lockett, M. (1988). Culture and the Problems of Chinese Management. Organization Studies, 9(4), 475-496. http://dx.doi.org/10.1177/017084068800900402

Lockett, M. (1990). The Nature of Chinese Culture, in Advances in Chinese Industrial Studies.

Luo, Y. D. (2000). Guanxi and business. Singapore: World Scientific. http://dx.doi.org/10.1142/9789812798060

Pratt, M. (1991). Conceptions of self within China and the United States: Contrasting foundations for adult education. International Journal of Intercultural Relations, 15, 285-310. http://dx.doi.org/10.1016/0147-1767(91)90003-Y

Pye, L. W. (1982). Chinese Commercial Negotiating Style. Oelgeschlager, Gunn and Hain, Cambridge, MA.

Redding, G. (1995). Overseas Chinese networks. Long Range Planning, 28(1), 61-69. http://dx.doi.org/10.1016/0024-6301(94)00071-C

Tang, Y. J. (1991). Confucianism, Buddhism, Taoism, Christianity and Chinese Culture. The Council for Research in Values and Philosophy, Washington, DC. 
Tjosvold, D., Hui, C., \& Law, K. S. (1998). Empowerment in the Manager-Employee Relationship in Hong Kong: Interdependence and Controversy. Journal of Social Psychology, 138, 624-636. http://dx.doi.org/10.1080/00224549809600417

Weber, M. (1951). The Religion of China: Confucianism and Taoism. Glencoe, IL: The Free Press.

Williams, C. C. (2008). A critical evaluation of competing representations of the relationship between formal and informal work. Community, Work \& Family, 11(1), 105-124 http://dx.doi.org/10.1080/13668800701785353

Wong, S. L. (1985). The Chinese family firm: A model. British Journal of Sociology, 36, 58-72. http://dx.doi.org/10.2307/590402

Zhang, Z. X. (2007). Barriers to organizational harmony: Mismatch between the values of leaders and employees. Peking University Business Review, (1), 24-29.

Zhao, \& Jensen, J. (2000). The Chinese approach to international business negotiations. Journal of Busniess Communication, 37(3), 209-236. http://dx.doi.org/10.1177/002194360003700302

\section{Copyrights}

Copyright for this article is retained by the author(s), with first publication rights granted to the journal.

This is an open-access article distributed under the terms and conditions of the Creative Commons Attribution license (http://creativecommons.org/licenses/by/3.0/). 